\title{
Methylenetetrahydrofolate reductase (MTHFR) C677T, A1298C and G1793A genotypes, and the relationship between maternal folate intake, tibia lead and infant size at birth
}

\author{
Katarzyna Kordas ${ }^{1}$, Adrienne S. Ettinger ${ }^{2,3}$, Héctor Lamadrid-Figueroa ${ }^{4}$, Martha M. Tellez-Rojo ${ }^{4}$, \\ Mauricio Hérnandez-Avila ${ }^{4}$, Howard $\mathrm{Hu}^{2,5}$ and Robert O. Wright ${ }^{2,3,6}$ \\ ${ }^{1}$ Pennsylvania State University, University Park, PA, USA \\ ${ }^{2}$ Harvard School of Public Health, Boston, MA, USA \\ ${ }^{3}$ Channing Laboratory, Brigham \& Women's Hospital and Harvard Medical School, Boston, MA, USA \\ ${ }^{4}$ National Institute of Public Health, Cuernavaca, Morelos, Mexico \\ ${ }^{5}$ University of Michigan School of Public Health, Ann Arbor, MI, USA \\ ${ }^{6}$ Children's Hospital, Boston, MA, USA \\ (Received 16 June 2008 - Revised 25 February 2009 - Accepted 25 February 2009 - First published online 2 April 2009)
}

\begin{abstract}
Small size at birth continues to be a problem worldwide and many factors, including reduced folate intake and $\mathrm{Pb}$ exposure, are associated with it. However, single factors rarely explain the variability in birth weight, suggesting a need for more complex explanatory models. We investigated environment-gene interactions to understand whether folate intake and maternal $\mathrm{Pb}$ exposure were associated with smaller newborn size in 474 women with uncomplicated pregnancies delivering term infants in Mexico City. We examined if folate intake modified the negative effects of maternal $\mathrm{Pb}$ burden on birth size. We also asked if maternal and infant methylenetetrahydrofolate reductase (MTHFR) genotypes (C677T, A1298C and G1793A) modified the effects of folate intake or Pb exposure on birth size. Women were aged 24.6 (SD 5.1) years; $43.5 \%$ were primiparous. Maternal blood $\mathrm{Pb}$ at delivery was 86 (SD 42) $\mu \mathrm{g} / \mathrm{l}$, with $26.7 \%$ having levels $\geq 100 \mu \mathrm{g} / \mathrm{l}$. Tibia Pb level was 9.9 (SD 9.8 ) $\mu \mathrm{g} / \mathrm{g}$. Of the women, $35.3 \%$ had folate intakes $<400 \mu \mathrm{g} / \mathrm{d}$. Birth weight was 3170 (SD 422) g. In covariate-adjusted regressions, higher folate intake was associated with higher birth weight $(\beta 0.04 ; P<0.05)$. Higher bone $\mathrm{Pb}$ was associated with lower birth weight $(\beta-4.9 ; P<0.05)$. Folate intake did not modify the effects of $\mathrm{Pb}$ on birth size, nor did MTHFR modify the association between $\mathrm{Pb}$ or folate intake on birth size. Although modest, the relationship between maternal nutrition, $\mathrm{Pb}$ burden and birth size does underscore the importance of environmental exposures to child health because patterns of fetal growth may affect health outcomes well into adulthood.
\end{abstract}

Dietary folate: Lead exposure: Pregnancy: Birth weight: Mexico

Small size at birth continues to be a problem even in populations with adequate energy and protein intakes. Many factors may account for small birth size, and it has been shown that low folate status or intake ${ }^{(1-4)}$ and excess $\mathrm{Pb}$ burden $^{(5-8)}$ are independently associated with reduced birth weight and length. As discussed by Andrews et al. ${ }^{(9)}$ the magnitude of the association between $\mathrm{Pb}$ and size at birth varied among studies and could not be explained by study design or confounding. Similarly, in some studies, folate intake or status explained only a small proportion of variability in outcome $^{(4)}$, suggesting that other factors may play a role.

Links between $\mathrm{Pb}$ exposure and folate intake have not been well studied, although there is evidence that folate metabolism may be related to $\mathrm{Pb}$ toxicity. In one study, serum folate levels were inversely associated with blood $\mathrm{Pb}$ concentrations among women of reproductive age ${ }^{(10)}$. A comparison of women who did and did not have fetuses with neural tube defects revealed higher $\mathrm{Pb}$ but lower folate levels in amniotic fluid at 15-20 weeks gestation $^{(11)}$. In addition, $\mathrm{Pb}$ levels were inversely correlated with both folate and vitamin $\mathrm{B}_{12}$ concentrations. More recently, higher erythrocyte folate concentration appeared to attenuate the adverse relationship between $\mathrm{Pb}$ exposure and cognitive performance of children from the Philippines ${ }^{(12)}$. Further evidence of a connection is found in studies of plasma homocysteine. Both reduced folate intake and increased $\mathrm{Pb}$ exposure are associated with higher plasma homocysteine ${ }^{(13,14)}$, which in turn is linked with adverse pregnancy outcomes ${ }^{(15,16)}$.

Variation in genes coding for folate-metabolising enzymes may be relevant because some polymorphisms of the methylenetetrahydrofolate reductase $(M T H F R)$ gene, such as the C677T or $\mathrm{A} 1298 \mathrm{C}$, are common ${ }^{(17)}$ and produce enzymes with lower metabolic activity ${ }^{(18)}$. Other variants, such as the G1793A, are less frequent and their functional significance is unclear ${ }^{(19,20)}$. However, studies examining the effects of folate on fetal growth among women and infants with different MTHFR genotypes have not produced consistent results ${ }^{(21-24)}$.

Abbreviations: $M T H F R$, methylenetetrahydrofolate reductase; SNP, single nucleotide polymorphism.

* Corresponding author: Dr Katarzyna Kordas, fax +1 814865 5870, email kxk48@psu.edu 
Gene-environment and nutrient-environment interactions are receiving increased attention because the main effects of genetic or environmental factors often explain only a small proportion of variability in health outcomes. The study of nutrient-environment interactions in particular may identify ways of preventing or intervening where environmental exposures have occurred. We investigated whether excess $\mathrm{Pb}$ burden was associated with smaller size at birth in 474 apparently healthy women with uncomplicated pregnancies who delivered term infants in Mexico City, and whether this relationship was modified by maternal folate intake during pregnancy. Finally, we tested the hypothesis that the associations between folate and birth size, and $\mathrm{Pb}$ and birth size would be modified by MTHFR genotype. We examined maternal and infant genotypes separately. Both genotypes are likely to interact with $\mathrm{Pb}$ because it easily crosses the placenta when the mother is exposed and with folate because it is supplied by the mother. These interactions may differentially influence infant size at birth.

\section{Experimental methods}

\section{Study sample and data collection}

Study participants were identified from among pregnant women receiving antenatal care between January 1994 and June 1995 at three hospitals in Mexico City that serve lowto-middle-income populations. The women were invited before giving birth to participate in a randomised, placebocontrolled trial of $\mathrm{Ca}$ supplementation beginning at 1-month postpartum. Women were excluded if they lived outside the metropolitan area, had no intention to breast-feed, or had any of the following: premature delivery, multiple fetuses, pre-eclampsia, psychiatric, renal or cardiac disease, gestational diabetes, history of urinary tract infections, history (family or self) of kidney stones, seizure disorders, ingestion of corticoids, high blood pressure $(>140 \mathrm{mmHg}$ systolic, $>90 \mathrm{mmHg}$ diastolic). Sample selection and data collection methods are described in detail elsewhere ${ }^{(5)}$.

Briefly, information on demographic characteristics, reproductive history and risk factors for $\mathrm{Pb}$ exposure were collected at baseline using a questionnaire. Newborn characteristics and estimated gestational age were extracted from medical records. Anthropometry, and maternal and umbilical blood were collected within $12 \mathrm{~h}$ of delivery. A semi-structured FFQ was administered and bone $\mathrm{Pb}$ measured at 1 month postpartum $( \pm 5 d)$ at the American British Cowdray Hospital. Archived blood samples were used for DNA extraction and MTHFR genotyping, performed at the Harvard-Partners Center for Genetics and Genomics (Boston, MA, USA). Table 1 shows the characteristics of the women and infants included in the study and those excluded from the study.

The present study was conducted according to the guidelines laid down in the Declaration of Helsinki and all procedures involving human subjects or patients were approved by the ethics review boards at the National Institute of

Table 1. Characteristics of study participants and those excluded from the study

(Mean values and standard deviations or percentages)

\begin{tabular}{|c|c|c|c|c|c|c|}
\hline & \multicolumn{3}{|c|}{ Included } & \multicolumn{3}{|c|}{ Excluded } \\
\hline & Subjects $(n)$ & Mean & SD & Subjects $(n)$ & Mean & SD \\
\hline \multicolumn{7}{|l|}{ Mothers } \\
\hline Age (years) $\dagger$ & 474 & $24 \cdot 6$ & $5 \cdot 1$ & 140 & 24.5 & $5 \cdot 3$ \\
\hline Pre-pregnancy BMI $\left(\mathrm{kg} / \mathrm{m}^{2}\right)$ & 474 & 28.0 & $3 \cdot 8$ & 93 & $28 \cdot 1$ & 3.8 \\
\hline Total schooling (years) & 474 & 9.4 & $3 \cdot 2$ & 140 & $8 \cdot 8^{*}$ & 3.1 \\
\hline Time living in Mexico (years) & 474 & $20 \cdot 5$ & $8 \cdot 3$ & 139 & $20 \cdot 7$ & 8.8 \\
\hline Ever smoking (\%) & 474 & $42 \cdot 8$ & & 139 & $48 \cdot 2$ & \\
\hline Prenatal supplements & 474 & & & 134 & & \\
\hline Percentage taking no supplements & & 63.7 & & & $72 \cdot 4$ & \\
\hline Percentage taking supplements $>2$ months & & $15 \cdot 8$ & & & $6 \cdot 7^{\star}$ & \\
\hline Percentage women reporting change in diet & 469 & $54 \cdot 8$ & & 133 & $60 \cdot 1$ & \\
\hline Primiparous (\%) & 474 & 43.5 & & 140 & 41.4 & \\
\hline Blood $\mathrm{Pb}$ at delivery $(\mu \mathrm{g} / \mathrm{l})$ & 471 & 86 & 42 & 136 & 84 & 38 \\
\hline Percentage with $\mathrm{Pb} \geq 100 \mu \mathrm{g} / \mathrm{l}$ & & $26 \cdot 7$ & & & $27 \cdot 2$ & \\
\hline Tibia $\mathrm{Pb}(\mu \mathrm{g} / \mathrm{g}$ bone $) \ddagger$ & 474 & 9.9 & $9 \cdot 8$ & 140 & $10 \cdot 2$ & $11 \cdot 1$ \\
\hline Median & & $9 \cdot 4$ & & & $9 \cdot 1$ & \\
\hline Postpartum calf circumference $(\mathrm{cm})$ & 474 & 34.1 & 3.3 & 119 & 34.0 & 3.8 \\
\hline Dietary folate intake $(\mu \mathrm{g} / \mathrm{d}) \S$ & 474 & 878 & 899 & 132 & $1382^{*}$ & 2193 \\
\hline Median intake & & 520 & & & 521 & \\
\hline \multicolumn{7}{|l|}{ Infants } \\
\hline Gestational age (weeks) & 321 & 39.4 & $1 \cdot 2$ & 251 & 39.4 & 1.2 \\
\hline Birth weight $(\mathrm{g})$ & 321 & 3170 & 422 & 293 & $3095^{\star}$ & 416 \\
\hline Percentage low birth weight & & 4.0 & & & $5 \cdot 8$ & \\
\hline Birth length $(\mathrm{cm})$ & 318 & 50.5 & $2 \cdot 3$ & 289 & $50 \cdot 2$ & $2 \cdot 4$ \\
\hline Percentage boys & 321 & 55.8 & & 289 & $54 \cdot 3$ & \\
\hline Cord blood $\mathrm{Pb}(\mu \mathrm{g} / \mathrm{l})$ & 282 & 68 & 37 & 224 & 64 & 32 \\
\hline Percentage with $\mathrm{Pb} \geq 100 \mu \mathrm{g} / \mathrm{l}$ & & 14.5 & & & $10 \cdot 7$ & \\
\hline
\end{tabular}

*Value was significantly different from that of the women or infants included in the study $(P<0.05)$.

† Refers to values at the time women were approached about possible study participation.

$\ddagger$ Measured at 1 month postpartum

$\S$ Measured at 1 month postpartum; refers to habitual intakes in the previous year. 
Public Health in Mexico, Harvard School of Public Health, and the participating hospitals. Written informed consent was obtained from all subjects and patients.

This is a cross-sectional analysis of data collected at baseline of a $\mathrm{Ca}$ supplementation trial, which ultimately enrolled 617 women. It expands on a previous report from our group on $\mathrm{Pb}$ exposure and infant birth weight, which included 315 motherinfant pairs from Mexico City ${ }^{(5)}$. Of the women available for the present study ( $n$ 617), those with a tibia $\mathrm{Pb}$ measurement, complete FFQ and plausible dietary intakes $(2092-20920 \mathrm{~kJ} / \mathrm{d}$ $(500-5000 \mathrm{kcal} / \mathrm{d}) ;<5000 \mu \mathrm{g}$ folate/d), at least two genotyped single nucleotide polymorphisms (SNP), information on gestational age and BMI, and a postpartum calf circumference measurement were eligible to participate. Three women did not have tibia $\mathrm{Pb}$ values, twenty-one had no reported or implausible dietary intakes, thirty-eight did not have at least two SNP, thirty-eight were missing gestational age, thirty-seven BMI values, and six postpartum calf circumference. The final sample included 474 women with complete data. For blood collection from neonates, we relied on nursing staff at the three hospitals and were able to obtain a convenience sample of umbilical cord bloods, with limited collection on weekends, at night and in the early morning. Due to these difficulties, we only included 321 newborns who had a blood sample for genotyping and a full set of covariates.

\section{Dietary assessment}

Maternal dietary intake was assessed by trained interviewers using a semi-quantitative FFQ with questions on usual food intakes in the previous year. The questionnaire was translated and validated for use in Spanish-speaking adult women ${ }^{(25)}$. The FFQ included 116 questions on the intake of eighty-two foods and beverages typical to urban Mexican diets. For each food listed, a portion size was specified and women were queried on the frequency of consumption (based on ten categories ranging from never, through monthly, weekly, to daily intakes). Nutrient intakes were calculated based on a nutrient database compiled by the National Institute of Nutrition in Mexico. Additional questions included: prenatal supplement use (type or brand, frequency, and duration), and whether women felt their diet had changed during the previous year, and why. Supplement use was included in the calculation of usual folate intakes.

\section{Blood lead measurements}

Blood $\mathrm{Pb}$ measurements were performed using graphite furnace atomic absorption spectrophotometry (model 3000; PerkinElmer, Wellesley, MA, USA) at the American British Cowdray Hospital Trace Metal Laboratory in Mexico City according to a previously described technique ${ }^{(26)}$. The laboratory participates in the Centers for Disease Control and Prevention blood $\mathrm{Pb}$ proficiency testing program administered by the Wisconsin State Laboratory of Hygiene (Madison, WI, USA) which provided external quality-control specimens varying from 20 to $880 \mu \mathrm{g} / \mathrm{l}$. The laboratory maintained acceptable precision and accuracy over the study period (correlation 0.98 ; mean difference $7 \cdot 1$ (SD 6.8) $\mu \mathrm{g} / \mathrm{l}$ ). The limit of detection for this technique was $8 \mu \mathrm{g} / \mathrm{l}$, with no individual values falling below this limit.

\section{Bone lead measurement}

Bone $\mathrm{Pb}$ measurements were performed at the American British Cowdray Hospital in Mexico City with a spot-source ${ }^{109} \mathrm{Cd} \mathrm{K} \mathrm{X-ray} \mathrm{fluorescence} \mathrm{(KXRF)} \mathrm{instrument} \mathrm{constructed}$ at Harvard University. Each woman underwent a $30 \mathrm{~min}$ in vivo measurement of the left mid-tibia shaft (cortical bone) and the left patella (trabecular bone). The instrument uses a $\mathrm{Cd} \gamma$-ray source to provoke bone to emit fluorescent photons, which are detected and counted. The details of the procedure are provided elsewhere ${ }^{(27)}$. Maternal tibia $\mathrm{Pb}$, but not patella or blood $\mathrm{Pb}$ concentration, was previously associated with birth weight in this population ${ }^{(5)}$; thus only tibia $\mathrm{Pb}$ concentrations are considered in this analysis. In addition to the bone $\mathrm{Pb}$ concentration ( $\mu \mathrm{g} \mathrm{Pb} / \mathrm{g}$ bone mineral), the instrument provides an estimate of uncertainty associated with each measurement that could be due to slight leg movements or adipose tissue. We excluded participants whose uncertainty estimates for tibia $\mathrm{Pb}$ exceeded $10 \mu \mathrm{g} \mathrm{Pb} / \mathrm{g}$ bone mineral. According to our standard quality-control procedures, the instrument was calibrated once per week with a 10 parts per million (ppm) phantom measured twenty consecutive times. Means and standard deviations were calculated to identify changes in accuracy or precision. Once per month, a set of calibration phantoms $(0,5,10,15,20,30$ and $50 \mathrm{ppm})$ was measured.

\section{Genotyping}

DNA extraction and genotyping were performed in the Harvard-Partners Center for Genetics and Genomics (Boston, MA, USA). High-molecular-weight DNA was extracted from leucocytes with PureGene Kits (Gentra Systems, Minneapolis, MN, USA). Extraction yielded an average of 20-40 $\mu \mathrm{g}$ DNA/ml whole blood. After DNA quantification, samples were adjusted to Tris-EDTA (TE) buffer, partitioned into samples, and stored at $-80^{\circ} \mathrm{C}$. A TaqMan platform was used to genotype the MTHFR C677T SNP rs1801133, A1298C rs1801131 and G1793A rs2274976. For quality assurance, a random sample of $5 \%$ was re-analysed and checked for discordance. In the present study, $97 \%$ of samples with adequate blood volume were successfully genotyped.

\section{Statistical analysis}

We used STATA 10 (StataCorp LP, College Station, TX, USA) for this analysis. We examined MTHFR allele distribution and tested allele frequencies using a $\chi^{2}$ statistic to confirm adherence to Hardy-Weinberg equilibrium principles. With this analysis we examined the following questions.

First, are folate intake and tibia $\mathrm{Pb}$ associated with infant size at birth? If so, does folate intake modify the negative effect of maternal $\mathrm{Pb}$ burden on newborn size? To address these questions, we modelled birth size (birth weight, length and head circumference) as a function of folate intake (model 1), tibia $\mathrm{Pb}$ (model 2) and their interaction. We considered an interaction to be significant at $P<0 \cdot 1$. Nonsignificant interaction terms were removed and regression models re-run testing the main effects of folate intake and tibia $\mathrm{Pb}$ (model 3). We did not adjust the significance levels for multiple comparisons. We used tibia $\mathrm{Pb}$ concentrations 
and folate intake levels both as continuous and categorical variables. For tibia $\mathrm{Pb}$, we used the median of the distribution, $9.4 \mu \mathrm{g} / \mathrm{g}$, as the cut-off. For folate, we used $400 \mu \mathrm{g} / \mathrm{d}$, which is the recommended daily intake level. We adjusted all regression models for the same variables as in our previous report $^{(5)}$ : gestational age, postpartum calf circumference, parity, maternal education and smoking, and in addition adjusted for maternal age, marital status, pre-pregnancy BMI and the sex of the infant.

Second, we examined if MTHFR genotypes were associated with birth size or modified the association between folate intake and birth size. For this analysis we assumed dominant effects of SNP (i.e. the effects were due to having any copy of the variant gene). We also examined birth size by maternal and infant haplotypes but found no significant differences. Thus, we compared the following groups: 677CC $v$. 677CT/ TT, 1298AA v. 1298AC/CC, and 1793GG v. 1793GA/AA.

Finally, we examined whether MTHFR genotype modified the association between folate intake, together with $\mathrm{Pb}$ exposure, and birth size. We performed all regression analyses stratified by genotype (677CC v. 677CT/TT, 1298AA v. $1298 \mathrm{AC} / \mathrm{CC}$, and $1793 \mathrm{GG}$ v. 1793GA/AA). Folate intake, tibia $\mathrm{Pb}$ levels and their interaction term (folate $\times \mathrm{Pb}$ ) were entered together in models predicting birth weight, height and head circumference. The folate $\times \mathrm{Pb}$ interaction term was removed if $P>0.1$ and models were re-run without it. As a final step, we tested the three-way interaction: MTHFR genotype $\times$ folate intake $\times$ tibia $\mathrm{Pb}$.

Regression diagnostics (residual $v$. fitted values, leverage $v$. residual squared, and augmented component-plus-residual plots, as well as checks for normality and homoskedasticity of the residuals) and tests of collinearity were performed. Regression diagnostics indicated acceptable model fits; regression assumptions were met.

\section{Results}

\section{Participant characteristics}

Women in the present study were aged 24.6 (SD 5.1) years at delivery. This sample was on average overweight and consisted of $40 \%$ first-time mothers. Most women had lived in Mexico City since early childhood, potentially being exposed to $\mathrm{Pb}$ most of their lives. Approximately $40 \%$ of the women reported ever smoking. Over $27 \%$ of the women and $13.7 \%$ of cord bloods were $\geq 100 \mu \mathrm{g} \mathrm{Pb} / \mathrm{l}$ blood, with a correlation between the two of 0.8 . Of the $44.8 \%$ of women who felt their diet had changed the previous year, $18.5 \%$ specifically mentioned pregnancy as the reason, and $6 \%$ mentioned economic hardship. Other changes included dieting, eating more fruits, less salt, or eating more. The study sample differed from those excluded on years of education, percentage taking prenatal supplements for $>2$ months, mean (but not median) folate intake and birth weight (all $P<0 \cdot 05)$. The difference in folate intake was due to the exclusion of implausible energy and folate values. The difference in birth weight was probably due to the exclusion of premature births.

The allele frequencies for maternal C677T, A1298C and G1793A were $0.59,0.11$ and 0.04 , respectively. Infants' allele frequencies were similar, at 0.59 for C677T, 0.11 for A1298C and 0.03 for G1793A. Allele distribution was in Hardy-Weinberg equilibrium.

\section{Main effects of folate intake and tibia lead on birth outcomes}

Birth weight was $4 \mathrm{~g}$ higher for every $100 \mu \mathrm{g} / \mathrm{d}$ increase in folate intake (Table 2; model 1), and women whose daily folate consumption fell in the highest quartile (1080$4898 \mu \mathrm{g} / \mathrm{d}$ ) had newborns who weighed $54.8 \mathrm{~g}$ more than women whose folate intake was in the lowest quartile $(<279 \mu \mathrm{g} / \mathrm{d})(P=0.08$ for trend). However, women who consumed dietary folate at levels below $400 \mu \mathrm{g} / \mathrm{d}$ did not differ on child birth weight from women consuming higher amounts (Table 2; model 1). In turn, each $1 \mu \mathrm{g} / \mathrm{g}$ difference in tibia $\mathrm{Pb}$ concentration was associated with a $4.9 \mathrm{~g}$ decrease in birth weight (Table 2; model 2). In a comparison among quartiles of tibia $\mathrm{Pb}$ concentrations, infants born to women with tibia $\mathrm{Pb}$ in the highest quartile $(15.6-76.5 \mu \mathrm{g} / \mathrm{g}$ bone) weighed $140 \mathrm{~g}$ less than infants born to women with tibia $\mathrm{Pb}$ in the lowest quartile (below $4 \cdot 1 \mu \mathrm{g} / \mathrm{g}$ bone) $(P<0 \cdot 001)$. Compared

Table 2. Covariate-adjusted associations between maternal folate intake, tibia lead concentrations and infant size at birth† ( $\beta$ Coefficients with their standard errors)

\begin{tabular}{|c|c|c|c|c|c|c|c|c|c|c|c|c|}
\hline \multirow[b]{3}{*}{ Predictor } & \multicolumn{4}{|c|}{ Birth weight $(g)(n 474)$} & \multicolumn{4}{|c|}{ Birth length $(\mathrm{cm})(n$ 470) } & \multicolumn{4}{|c|}{ Head circumference $(\mathrm{cm})(n$ 455) } \\
\hline & \multicolumn{2}{|c|}{ Continuous } & \multicolumn{2}{|c|}{ Categorical } & \multicolumn{2}{|c|}{ Continuous } & \multicolumn{2}{|c|}{ Categorical } & \multicolumn{2}{|c|}{ Continuous } & \multicolumn{2}{|c|}{ Categorical } \\
\hline & $\beta$ & SE & $\beta$ & SE & $\beta$ & SE & $\beta$ & SE & $\beta$ & SE & $\beta$ & SE \\
\hline \multicolumn{13}{|l|}{ Model $1 \mp \S$} \\
\hline $\begin{array}{l}\text { Folate intake }(\mu \mathrm{g} / \mathrm{d}) \\
\text { Model } 2 \ddagger \|\end{array}$ & $0.04^{*}$ & 0.02 & $21 \cdot 7$ & $38 \cdot 3$ & 0.0001 & 0.0001 & -0.21 & $0 \cdot 20$ & 0.0001 & 0.001 & 0.03 & $0 \cdot 15$ \\
\hline $\begin{array}{l}\text { Tibia Pb }(\mu \mathrm{g} / \mathrm{g}) \\
\text { Model } 3 \ddagger \rrbracket\end{array}$ & $-4 \cdot 9^{\star \star}$ & $1 \cdot 8$ & $-99 \cdot 1^{\star \star}$ & $35 \cdot 5$ & -0.02 & 0.01 & -0.32 & $0 \cdot 20$ & -0.01 & 0.01 & $-0.27^{\star}$ & 0.13 \\
\hline Folate intake $(\mu \mathrm{g} / \mathrm{d})$ & $0.04^{\star}$ & 0.02 & 34.0 & $38 \cdot 3$ & 0.0001 & 0.0001 & -0.17 & 0.22 & 0.0001 & 0.0001 & 0.07 & 0.15 \\
\hline Tibia $\mathrm{Pb}(\mu \mathrm{g} / \mathrm{g})$ & $-4 \cdot 77^{\star \star}$ & $1 \cdot 8$ & $-102 \cdot 6^{\star \star}$ & $35 \cdot 7$ & -0.02 & 0.01 & -0.30 & $0 \cdot 20$ & -0.01 & 0.01 & $-0.28^{*}$ & 0.14 \\
\hline
\end{tabular}

${ }^{\star} P<0.05,{ }^{* *} P<0.01$.

†Folate intake and tibia $\mathrm{Pb}$ values model as continuous variables or categorical variables (folate $<400 \mu \mathrm{g} / \mathrm{d}$, tibia $\mathrm{Pb} \geq 9 \cdot 4 \mu \mathrm{g} / \mathrm{g}$ )

$\ddagger$ Adjusted for maternal age, pre-pregnancy BMI, height, total years of schooling, parity, marital status, ever smoking, postpartum calf circumference, infant gestational age and sex of infant.

$\S$ Model 1 represents the covariate-adjusted main effect of folate intake on birth size.

$\|$ Model 2 represents the covariate-adjusted main effect of tibia $\mathrm{Pb}$ concentrations on birth size.

ๆ Model 3 represents the covariate-adjusted relationship between folate intake and tibia $\mathrm{Pb}$ with birth size. 
with women with tibia $\mathrm{Pb}$ below $9.4 \mu \mathrm{g} / \mathrm{g}$ (median), those above $9.4 \mu \mathrm{g} / \mathrm{g}$ had infants who weighed, on average, $99 \mathrm{~g}$ less.

Maternal folate intake or maternal tibia $\mathrm{Pb}$ concentrations were not associated with birth length. Folate intake was not associated with head circumference, but women with tibia $\mathrm{Pb}>9.4 \mu \mathrm{g} / \mathrm{g}$ had newborns with smaller heads than women with lower $\mathrm{Pb}$ burdens (Table 2; model 2). When folate intake and tibia $\mathrm{Pb}$ were modelled together, they did not attenuate each other's association with birth size (Table 2; model 3). There were no significant interactions between folate intake and tibia $\mathrm{Pb}$ on any outcomes (data not shown).

\section{Relationship between folate intake and}

methylenetetrahydrofolate reductase (MTHFR), and tibia lead and MTHFR

Neither maternal nor infant MTHFR genotype was associated with infant size at birth (data not shown). We also tested twoway interactions: folate intake $\times M T H F R$ genotype and tibia $\mathrm{Pb} \times$ MTHFR genotype on birth weight (Table 3), birth length and head circumference (data not shown). The MTHFR genotype did not modify the effect of folate intake on any aspect of newborn size. We also found no significant interactions between MTHFR genotype and tibia $\mathrm{Pb}$ on newborn size.

Relationship between folate intake, tibia lead and birth size, by genotype

We examined the interactions between folate intake and tibia $\mathrm{Pb}$ on birth size within each maternal and infant MTHFR genotype. We tested but found no significant three-way interactions between folate intake, tibia $\mathrm{Pb}$, and each of the SNP. Furthermore, finding no significant folate intake $\times \mathrm{Pb}$ interactions, we examined only the main effects of folate intake and tibia $\mathrm{Pb}$ within the SNP strata (Table 4). There were no consistent associations between folate intake and birth weight by maternal MTHFR genotype: only two of the six regression coefficients were significant and all were similar across strata (Table 4). For women with 677CC, 1298AA and 1793GG genotypes, the association between tibia $\mathrm{Pb}$ and birth weight appeared more adverse than for women with 677CT/TT, 1298AC/CC and 1793GA/AA genotypes. Analyses by the infants' genotype (Table 4) revealed no associations between maternal folate intake and birth weight in genotype strata. Tibia $\mathrm{Pb}$ was negatively associated with birth weight but there were no clear cross-strata differences in coefficients.

The association between maternal folate intake and birth length was not significant and did not differ by maternal or infant SNP (data not shown). There were no consistent differences by genotype on the association between tibia $\mathrm{Pb}$ and birth length. The relationship between folate intake or tibia $\mathrm{Pb}$ and head circumference was not statistically significant within MTHFR strata (data not shown).

\section{Discussion}

The present study examined nutrient-environment, genenutrient and gene-environment interactions in determining newborn size. We confirmed that maternal folate intake is positively associated with birth weight and that maternal $\mathrm{Pb}$

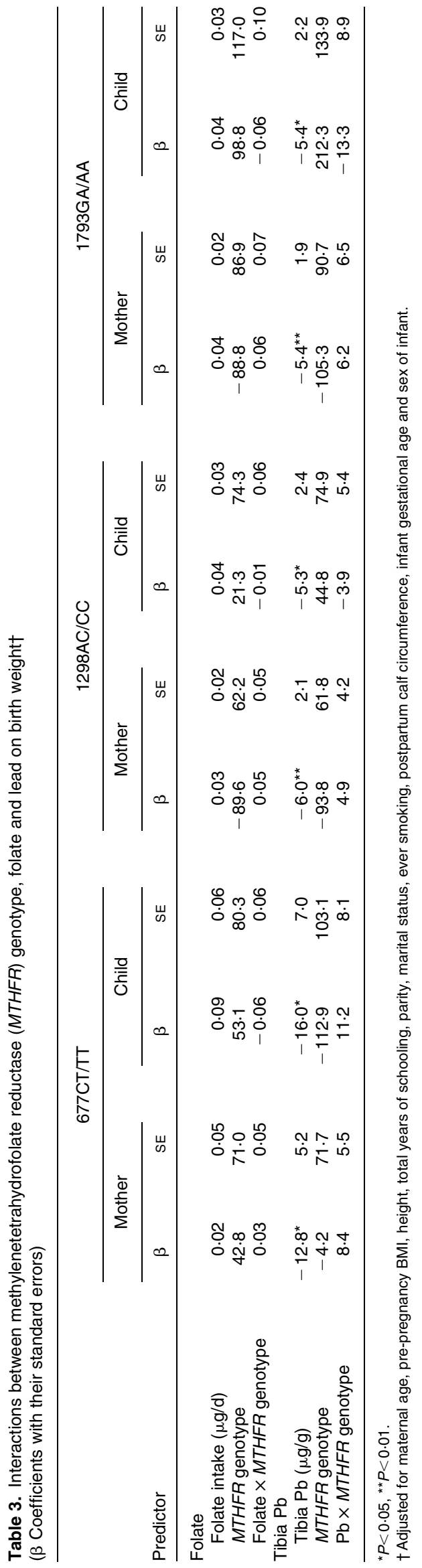


Table 4. Covariate-adjusted relationship between folate intake, tibia lead and birth weight, by maternal and infant methylenetetrahydrofolate reductase (MTHFR) genotype†

( $\beta$ Coefficients with their standard errors)

\begin{tabular}{|c|c|c|c|c|c|c|c|c|c|c|c|c|}
\hline & \multicolumn{2}{|c|}{$677 \mathrm{CC}$} & \multicolumn{2}{|c|}{ 677CT/TT } & \multicolumn{2}{|c|}{ 1298AA } & \multicolumn{2}{|c|}{ 1298AC/CC } & \multicolumn{2}{|c|}{ 1793GG } & \multicolumn{2}{|c|}{ 1793GA/AA } \\
\hline & $\beta$ & SE & $\beta$ & SE & $\beta$ & SE & $\beta$ & SE & $\beta$ & SE & $\beta$ & SE \\
\hline \multicolumn{13}{|l|}{ Mothers } \\
\hline$n$ & \multicolumn{2}{|c|}{66} & \multicolumn{2}{|c|}{381} & \multicolumn{2}{|c|}{373} & \multicolumn{2}{|c|}{92} & \multicolumn{2}{|c|}{438} & \multicolumn{2}{|c|}{36} \\
\hline Folate $(\mu \mathrm{g} / \mathrm{d})$ & 0.04 & 0.06 & $0.05^{\star}$ & 0.02 & 0.03 & 0.02 & $0 \cdot 10^{*}$ & 0.05 & 0.04 & 0.02 & -0.02 & $0 \cdot 10$ \\
\hline Tibia $(\mu \mathrm{g} / \mathrm{g})$ & $-14 \cdot 8^{\star}$ & $6 \cdot 3$ & $-4 \cdot 3^{\star}$ & 1.9 & $-6 \cdot 3^{\star *}$ & $2 \cdot 1$ & $1 \cdot 1$ & $3 \cdot 8$ & $-5 \cdot 5^{\star \star}$ & 1.9 & $6 \cdot 9$ & $6 \cdot 8$ \\
\hline Infants & & & & & & & & & & & & \\
\hline$n$ & \multicolumn{2}{|c|}{50} & \multicolumn{2}{|c|}{266} & \multicolumn{2}{|c|}{250} & \multicolumn{2}{|c|}{69} & \multicolumn{2}{|c|}{298} & \multicolumn{2}{|c|}{23} \\
\hline Folate $(\mu \mathrm{g} / \mathrm{d})$ & 0.05 & 0.05 & 0.03 & 0.03 & 0.03 & 0.03 & 0.06 & 0.05 & 0.04 & 0.03 & -0.09 & 0.17 \\
\hline Tibia $(\mu \mathrm{g} / \mathrm{g})$ & $-15 \cdot 2^{\star}$ & $6 \cdot 3$ & $-4 \cdot 7^{\star}$ & $2 \cdot 4$ & $-5 \cdot 5^{\star}$ & $2 \cdot 4$ & -7.9 & $5 \cdot 8$ & -5.4 & $2 \cdot 3$ & $-18 \cdot 8$ & $11 \cdot 1$ \\
\hline
\end{tabular}

${ }^{\star} P<0.05,{ }^{\star *} P<0.01$

†Adjusted for maternal age, pre-pregnancy BMI, height, total years of schooling, parity, marital status, ever smoking, postpartum calf circumference, gestational age and sex of infant.

exposure is associated with lower newborn size, particularly birth weight. In addition, the present study contributes to our understanding of how predictors of newborn size interact to affect these outcomes. We found that maternal folate intake does not modify the negative effects of $\mathrm{Pb}$ on birth size despite a reported interaction from a study on cognitive performance in children ${ }^{(12)}$. We also found that neither maternal nor infant MTHFR genotype alone was associated with newborn size and that these genotypes did not modify the effects of folate intake or $\mathrm{Pb}$ on newborn size; however, this may be due in part to limited power to detect an interaction.

In the present study, differences in newborn size in relation to maternal folate intake and $\mathrm{Pb}$ exposure were modest. Birth weight was higher by $54.8 \mathrm{~g}$ among women with high (1080$4898 \mu \mathrm{g} / \mathrm{d}) v$. low $(<279 \mu \mathrm{g} / \mathrm{d})$ daily folate intake. In turn, infant birth weight was lower by $140 \mathrm{~g}$ among women with high tibia $\mathrm{Pb}$ levels $(15.6-76.5 \mu \mathrm{g} / \mathrm{g})$ compared with those with low tibia $\mathrm{Pb}(<4 \cdot 1 \mu \mathrm{g} / \mathrm{g})$. Even modest declines in newborn size, however, could affect later development and disease at the population level, particularly in an urban setting such as Mexico City, where pregnant women may have multiple environmental exposures and micronutrient deficiencies.

Numerous studies show positive associations between maternal folate intake and biomarkers, and fetal and newborn size ${ }^{(1-3,28)}$. Supplementation with folate also increases birth weight and prevents low birth weight and preterm birth $^{(29,30)}$. The present results are consistent with those findings. Unlike others ${ }^{(21,23,24)}$, however, we did not find effect modification by MTHFR genotype, possibly because we assessed folate intake rather than biomarkers of folate status or because folate intake was fairly high in this population. Of the women, $35.3 \%$ had folate intakes below $400 \mu \mathrm{g} / \mathrm{d}$, which is lower than the prevalence of inadequate intakes in low-income US women ${ }^{(28)}$. Folate intake in our sample (median $520 \mu \mathrm{g} / \mathrm{d}$ ) was also higher than previously reported for Mexico City women (median $187.7 \mu \mathrm{g} / \mathrm{d}$ ) ${ }^{(31)}$.

Of particular interest in the present study was the examination of folate intake $\times \mathrm{Pb}$ interactions in affecting newborn size because such interactions would have important implications for prenatal care of Pb-exposed women. Two studies have found inverse correlations between folate status and $\mathrm{Pb}$ levels in women who were of reproductive age $\mathrm{e}^{(10)}$ or pregnant ${ }^{(11)}$. Another showed that folate status attenuated the adverse effect of $\mathrm{Pb}$ on children's cognitive performance ${ }^{(12)}$. In the present study, folate intake and maternal $\mathrm{Pb}$ burden were not correlated and we found that folate intake did not modify the association between tibia $\mathrm{Pb}$ and newborn size. It is unclear whether the lack of effect modification in the present study was due to how we measured folate status (intake $v$. serum or blood indicators), to the range of folate intakes and $\mathrm{Pb}$ exposures among the study women, or to birth size being a less sensitive outcome than cognitive performance. Also, the processes by which $\mathrm{Pb}$ produces neurotoxicity probably differ from those exerted on fetal growth, and as such the present study does not contradict prior reports of folate $\times \mathrm{Pb}$ interactions on neurodevelopmental outcomes.

In terms of $\mathrm{Pb}$ effects on newborn size, our group has previously shown that long-term $\mathrm{Pb}$ exposure is associated with lower birth weight ${ }^{(5)}$ and length ${ }^{(6)}$. Our birth-weight findings are consistent with other studies $^{(7,8)}$ although different measures of $\mathrm{Pb}$ exposure were used, and investigations of birth length and head circumference in $\mathrm{Pb}$-exposed populations are limited. $\mathrm{Pb}$ exposure levels in the present study were higher than in US populations ${ }^{(32,33)}$. Very few studies measure bone $\mathrm{Pb}$, so comparisons with other populations are difficult. It is unclear whether similar findings on newborn size would be present in populations with lower $\mathrm{Pb}$ exposures.

Despite finding no statistically significant interactions between tibia $\mathrm{Pb}$ and MTHFR genotypes, we believe that the differing regression coefficients for the $\mathrm{Pb}$-birth weight relationship in maternal genotype strata deserve further study with larger samples. The possible protective effect of MTHFR polymorphisms on birth weight in prenatal $\mathrm{Pb}$ exposure should be investigated in studies that include biomarkers of both $\mathrm{Pb}$ and folate status. $\mathrm{Pb} \times M T H F R$ interactions are potentially important in populations characterised by a high prevalence of variant genotypes, particularly the 677CT/TT. The allele frequency for this variant in our population was 0.59 , in line with other studies of Mexican populations, but much higher than among Northern Europeans and Africans ${ }^{(17)}$. The allele frequency for $1298 \mathrm{AC} / \mathrm{CC}$ was also in line with other studies ${ }^{(17)}$.

A potential limitation of the present study was the use of a 12-month recall period to estimate folate intakes in pregnant women. The consumption of foods changed between the first and second trimesters for about $50 \%$ of Boston women ${ }^{(34)}$ 
and between pre- to mid-pregnancy in women from rural New York ${ }^{(35)}$. In the present study, $44.8 \%$ of women reported changes in diet in the previous year, but this was unrelated to newborn size. The concern with an FFQ that has a longer recall period is that it may inadequately reflect intakes over that period and that important effects may be missed when diet is not assessed more frequently. The recall period in the present study may be another reason why we did not find an effect modification of folate intake by MTHFR genotype, particularly if intakes in one trimester of pregnancy are more relevant to this relationship than in another.

In summary, we found that higher maternal folate intake was positively, but higher bone $\mathrm{Pb}$ concentrations were negatively, associated with newborn size. Although the associations between maternal nutrition and $\mathrm{Pb}$ burden and child size at birth were modest, they underscore the importance of environmental exposures to child health, because birth outcomes such as weight predict postnatal growth and development of the child, and disease risk in adulthood.

\section{Acknowledgements}

The present study was supported by the US National Institute of Environmental Health Sciences (NIEHS; grant nos. P42-ES05947, P30-ES 00002, K23-ES000381, RO1-ES014930, RO1-ES013744 and RO1-ES007821), Consejo Nacional de Ciencia y Tecnología (CONACyT) grant 4150M9405 and CONSERVA, Department of Federal District, Mexico. We thank the American British Cowdray Hospital (Mexico City) for use of their research facilities.

K. K. analysed the data and drafted the manuscript. A. S. E. assisted with data collection and interpretation, and manuscript editing. H. L.-F. and M. M. T.-R. assisted with data interpretation and manuscript editing. M. H.-A. and H. H. obtained funding for the birth cohort. R. O. W. obtained funding for genotyping.

The authors declare no competing financial interests.

\section{References}

1. Neggers YH, Goldenberg RL, Tamura T, et al. (1997) The relationship between maternal dietary intake and infant birthweight. Acta Obstetr Gynecol Scand 165, 71S-75S.

2. Relton CL, Pearce MS \& Parker L (2005) The influence of erythrocyte folate and serum vitamin $B_{12}$ status on birth weight. Br J Nutr 93, 593-599.

3. Sram RJ, Binkova B, Lnenickova Z, et al. (2005) The impact of plasma folate levels of mothers and newborns on intrauterine growth retardation and birth weight. Mutat Res 591, 302-310.

4. Scholl TO, Leskiw M, Chen X, et al. (2005) Oxidative stress, diet, and the etiology of preeclampsia. Am J Clin Nutr 81, 1390-1396.

5. González-Cossío T, Peterson KE, Sanín LH, et al. (1997) Decrease in birth weight in relation to maternal bone-lead burden. Pediatrics 100, 856-862.

6. Hernández-Avila M, Peterson KE, González-Cossío T, et al. (2002) Effect of maternal bone lead on length and head circumference of newborns and 1-month-old infants. Arch Environ Health 57, 482-488.

7. Berkowitz Z, Price-Green P, Bove FJ, et al. (2006) Lead exposure and birth outcomes in five communities in Shoshone County, Idaho. Int J Hyg Environ Health 209, 123-132.
8. Jelliffe-Pawlowski LL, Miles SQ, Courtney JG, et al. (2006) Effect of magnitude and timing of maternal pregnancy blood lead $(\mathrm{Pb})$ levels on birth outcomes. J Perinatol 26, 154-162.

9. Andrews KW, Savitz DA \& Hertz-Picciotto I (1994) Prenatal lead exposure in relation to gestational age and birth weight: a review of epidemiologic studies. Am J Ind Med 26, 13-32.

10. Lee MG, Chun OK \& Song WO (2005) Determinants of the blood lead level of US women of reproductive age. J Am Coll Nutr 24, 1-9.

11. Dawson EB, Evans DR, Harris WA, et al. (1999) Amniotic fluid $\mathrm{B}_{12}$, calcium, and lead levels associated with neural tube defects. Am J Perinatol 16, 373-378.

12. Solon O, Riddell TJ, Quimbo SA, et al. (2008) Associations between cognitive function, blood lead concentration, and nutrition among children in the Central Philippines. J Pediatr 152, $237-243$

13. Homocysteine Lowering Trialists' Collaboration (2002) Dosedependent effects of folic acid on blood concentrations of homocysteine: a meta-analysis of the randomized trials. Am J Clin Nutr 82, 806-812.

14. Chia SE, Ali SM, Lee B, et al. (2007) Association of blood lead and homocysteine levels among lead exposed subjects in Vietnam and Singapore. BMJ 64, 688-693.

15. Infante-Rivard C, Rivard GE, Gauthier R, et al. (2003) Unexpected relationship between plasma homocysteine and intrauterine growth restriction. Clin Chem 49, 1476-1482.

16. Murphy MM, Scott JM, Arija V, et al. (2004) Maternal homocysteine before conception and throughout pregnancy predicts fetal homocysteine and birth weight. Clin Chem 50, 1406-1412.

17. Gueant-Rodriguez RM, Gueant JL, Debard R, et al. (2006) Prevalence of methylenetetrahydrofolate reductase $677 \mathrm{~T}$ and 1298C alleles and folate status: a comparative study in Mexican, West African, and European populations. Am J Clin Nutr 83, 701-707.

18. Weisberg I, Tran P, Christensen B, et al. (1998) A second genetic polymorphism in methylenetetrahydrofolate reductase (MTHFR) associated with decreased enzyme activity. Mol Genet Metab 64, 169-172.

19. Xu WH, Shrubsole MJ, Xiang YB, et al. (2007) Dietary folate intake, MTHFR genetic polymorphisms, and the risk of endometrial cancer among Chinese women. Cancer Epidemiol Biomarkers Prev 16, 281-287.

20. Bottiger AK, Hurtig-Wennlof A, Sjostrom M, et al. (2007) Association of total plasma homocysteine with methylenetetrahydrofolate reductase genotypes $677 \mathrm{C}>\mathrm{T}, 1298 \mathrm{~A}>\mathrm{C}$, and $1793 \mathrm{G}>\mathrm{A}$ and the corresponding haplotypes in Swedish children and adolescents. Int J Molec Med 19, 659-665.

21. Nurk E, Tell GS, Refsum H, et al. (2004) Associations between maternal methylenetetrahydrofolate reductase polymorphisms and adverse outcomes of pregnancy: the Hordaland homocysteine study. Am J Med 117, 26-31.

22. Glanville T, Yates Z, Ovadia L, et al. (2006) Fetal folate C677T methylenetetrahydrofolate reductase gene polymorphysim and low birth weight. J Obstet Gynaecol 26, 11-14.

23. Relton CL, Pearce MS, Burn J, et al. (2005) An investigation of folate-related genetic factors in the determination of birthweight. Paediatr Perinat Epidemiol 19, 360-367.

24. Engel SM, Olshan AF, Siega-Riz AM, et al. (2006) Polymorphisms in folate metabolizing genes and risk for spontaneous preterm and small-for-gestational age birth. Am J Obstet Gynecol 195, $1231-1241$.

25. Hernandez-Avila M, Romieu I, Parra S, et al. (1998) Validity and reproducibility of a food frequency questionnaire to assess dietary intake of women living in Mexico City. Salud Pública Méx 40, 133-140.

26. Miller DT, Paschal DC, Gunter EW, et al. (1987) Determination of lead in blood using electrothermal atomisation 
atomic absorption spectrometry with a L'vov platform and matrix modifier. Analyst 112, 1697-1699.

27. Aro AC, Todd AC, Amarasiriwardena C, et al. (1994) Improvements in the calibration of ${ }^{109} \mathrm{Cd} \mathrm{K} \mathrm{X-ray} \mathrm{fluorescence} \mathrm{systems}$ for measuring bone lead in vivo. Phys Med Biol 39, 2263-2271.

28. Scholl TO, Hediger ML, Schall JI, et al. (1996) Dietary and serum folate: their influence on the outcome of pregnancy. $\mathrm{Am}$ J Clin Nutr 63, 520-525.

29. Rolschau J, Kristoffersen K, Ulrich M, et al. (1999) The influence of folic acid supplement on the outcome of pregnancies in the county of Funen in Denmark. Part I. Eur J Obstet Gynecol Reprod Biol 87, 105-110.

30. Charles DH, Ness AR, Campbell D, et al. (2005) Folic acid supplements in pregnancy and birth outcome: re-analysis of a large randomised controlled trial and update of Cochrane review. Paediatr Perinat Epidemiol 19, 112-124.
31. Baquera S, Rivera JA, Espinosa-Montero J, et al. (2003) Energy and nutrient consumption in Mexican women 12-49 years of age: analysis of the National Nutrition Survey 1999. Salud Pública Méx 45, S530-S539.

32. Harville EW, Hertz-Picciotto I, Schramm M, et al. (2005) Factors influencing the difference between maternal and cord blood lead. Occup Environ Med 62, 263-269.

33. Schell LM, Denham M, Stark AD, et al. (2003) Maternal blood lead concentration, diet during pregnancy, and anthropometry predict neonatal blood lead in a socioeconomically disadvantaged population. Environ Health Perspect 111, 195-200.

34. Rifas-Shiman SL, Rich-Edwards JW, Willett WC, et al. (2006) Changes in dietary intake from the first to the second trimester of pregnancy. Paediatr Perinat Epidemiol 20, 35-42.

35. Olson CM (2005) Tracking of food choices across the transition to motherhood. J Nutr Educ Behav 37, 129-136. 